\title{
Frédéric Plessis, poète et romancier, sous la direction de Yann Mortelette
}

\section{Ida Merello}

\section{Q OpenEdition}

1 Journals

\section{Edizione digitale}

URL: http://journals.openedition.org/studifrancesi/1592

DOI: 10.4000/studifrancesi. 1592

ISSN: 2421-5856

\section{Editore}

Rosenberg \& Sellier

\section{Edizione cartacea}

Data di pubblicazione: 1 novembre 2014

Paginazione: 626-627

ISSN: 0039-2944

\section{Notizia bibliografica digitale}

Ida Merello, «Frédéric Plessis, poète et romancier, sous la direction de Yann Mortelette », Studi Francesi [Online], 174 (LVIII | III) | 2014, online dal 01 novembre 2014, consultato il 18 septembre 2020. URL http://journals.openedition.org/studifrancesi/1592 ; DOI : https://doi.org/10.4000/studifrancesi.1592

Questo documento è stato generato automaticamente il 18 settembre 2020.

\section{(c) (i) (9)}

Studi Francesi è distribuita con Licenza Creative Commons Attribuzione - Non commerciale - Non opere derivate 4.0 Internazionale. 


\title{
Frédéric Plessis, poète et romancier, sous la direction de Yann Mortelette
}

\author{
Ida Merello
}

\section{NOTIZIA}

Frédéric Plessis, poète et romancier, sous la direction de Yann MORTELETTE, Rennes, Presses univ., pp. 204.

1 Il volume accoglie interventi di Yann MORTELETTE (Frédéric Plessis, un écrivain brestois à redécouvrir, pp. 9-25), Maëlle venNEGues (Le fonds Frédéric Plessis de la bibliothèque municipale de Brest, pp. 27-36), Edgar PICH (Quelques considérations sur Frédéric Plessis et la métrique, pp. 37-50), Marie-France DE PALACIO (Ces petits poèmes où brille quelque beauté d'art et d'émotion: l'épitaphe latine chez Frédéric Plessis, pp. 51-68), Yann MORTELETTE (Frédéric Plessis et le Parnasse, pp. 69-82), Michael Pakenham (Le deuxième Parnasse contemporain vu par Frédéric Plessis et Arthur Rimbaud, pp. 83-90), Jean-Luc STEINMETZ (Frédéric Plessis, une rencontre sans lendemain, pp. 91-102), Jean-Louis MEUNIER (Morale, mère et société dans Angèle de Blindes, pp. 103-112), Alain-Gabriel моот (La représentation de la femme dans Le Mariage de Léonie, pp. 113-118), Marie FLAMENT (La vie rêvée de Caroline Gévrot, pp. 119-126), Jean BALcou (Frédéric Plessis, entre Anatole France et Jean Psichari, pp. 127-136), Jean-Pierre DupouY (Le culte de la règle : quelques professions de foi de Frédéric Plessis dans ses lettres à Auguste Dupouy, pp. 137-148). Seguono alcuni documenti: una prefazione di Plessis a una raccolta di versi inediti, un brano di corrispondenza tra Plessis e Heredia, alcune note di Plessis su Leconte de Lisle. Sarebbe difficile entrare nel dettaglio della quantità di articoli che vengono a formare, nel loro insieme, una ricca monografia, che ha il pregio di presentare una figura molto appartata, ma in realtà significativa nel sistema di rapporti della poesia della seconda metà dell'Ottocento e del primo Novecento. La catalogazione di un imponente fondo di documenti ha permesso di consultare per la prima volta non solo quaderni di appunti, ma anche articoli e brani di corrispondenza che fanno luce sul ruolo di mediatore tra la cultura parigina e quella 
regionale bretone che Plessis ha svolto per lunghi decenni. Oltre a essere un erudito latinista, esperto di metrica latina, Plessis ha infatti diffuso le innovazioni poetiche parigine, avanzando persino alcune riserve, come ha verificato M. PAKENHAM, sulla scarsa quantità di innovazione poetica presente nella raccolta del secondo Parnasse contemporain. J.-L. STEINMETZ ricostruisce invece, sulla base dei documenti, l'atmosfera di Douarnenez, dove Mallarmé stava probabilmente componendo Le Coup de dés e Plessis proseguiva sul versante della poesia tradizionale. Y. MORTELETTE definisce il rapporto col Parnasse, sulla base delle affermazioni dello stesso Plessis nella sua corrispondenza, e di quelle del suo amico di scuola e critico del movimento, Marc Souriau. L'attenta lettura della raccolta La Lampe d'argile permette all'A. di mostrare il piccolo margine di innovazione, nel timore delle novità più clamorose della nuova poesia.

2 Anche gli studi sui romanzi consentono un buon colpo d'occhio, mostrando, oltre la forte componente autobiografica, anche i suoi intenti sociali e i riferimenti letterari. 